\title{
Evaluation of Topical Application of Azadirachta indica (Neem) in Prevention of Gingivitis: A Randomized Control Trial
}

\author{
Vibha Singh', Anjani Kumar Pathak ${ }^{2}$, Kopal Goel ${ }^{3}$, Mahesh Pal ${ }^{4}$ \\ ${ }^{1}$ King George's Medical University, Lucknow, India \\ ${ }^{2}$ Department of Periodontology, Faculty of Dental Sciences, King George's Medical University, Lucknow, India \\ ${ }^{3}$ Sardar Patel Post Graduate Institute of Dental and Medical Sciences, Lucknow, India \\ ${ }^{4}$ Phytochemistry Division, CSIR-National Botanical Research Institute, Lucknow, India \\ Email: vibhasin ghraghuvanshi@gmail.com
}

How to cite this paper: Singh, V., Pathak, A.K., Goel, K. and Pal, M. (2019) Evaluation of Topical Application of Azadirachta indica (Neem) in Prevention of Gingivitis: A Randomized Control Trial. Open Journal of Stomatology, 9, 249-259.

https://doi.org/10.4236/ojst.2019.911026

Received: September 11, 2019

Accepted: November 4, 2019

Published: November 7, 2019

Copyright $\odot 2019$ by author(s) and Scientific Research Publishing Inc. This work is licensed under the Creative Commons Attribution International License (CC BY 4.0).

http://creativecommons.org/licenses/by/4.0/

\begin{abstract}
Background: The purpose of the present study was to envisage the anti-plaque and anti-inflammatory properties of neem (Azadirachta) in the form of a mouth gel. Materials and Methods: A total of 60 subjects ( 33 males and 27 females) from age group 19 - 35 years, suffering from mild to moderate gingivitis were randomly divided into two groups. Group A $(\mathrm{n}=30)$ participants were advised experimental (neem) gel and Group B $(n=30)$ participants were advised $0.2 \%$ chlorhexidine gel. All the clinical parameters (the gingival index by Loe and Silness [1], Plaque index by Silness and Loe [2] and sulcus bleeding index by Muhlemann H. R. and Sen S. [3]) were recorded at baseline, on the $14^{\text {th }}$ day and $21^{\text {st }}$ day by the same clinician in both groups. Results: on intragroup comparison the gingival index, plaque index and sulcus bleeding index decrease significantly in both the groups in all assessed periods. On intergroup comparison the indices did not differ significantly at baseline but after $2^{\text {nd }}$ and $3^{\text {rd }}$ week, the indices in Group B decrease more than the group A, which was statistically significant. Conclusion: Based on the observations of our study, it can be concluded that chlorhexidine gluconate as well as neem gel can be effectively used as an adjunct to mechanical plaque control in prevention of plaque and gingivitis. chlorhexidine gluconate gel has been found to be more effective when antiplaque and anti-inflammatory properties were considered. The effect of neem observed maybe because of its anti-inflammatory action. The antiplaque action of chlorhexidine gluconate is due to its substantivity. Substantivity of neem is required to be further studied.
\end{abstract}




\section{Keywords}

Azadirachta, Gingivitis. Anti Plaque

\section{Introduction}

Gingivitis is a form of periodontal disease which affects most of the children and adult populations. It usually precedes periodontitis which can lead to tooth loss. Bacterial plaque is the major etiological factor in gingivitis [4].

Mechanical removal of bacterial plaque is an established method for maintaining good oral hygiene. However, studies have shown that the accurate and complete mechanical plaque control methods are difficult to follow because dexterity necessitates for good oral hygiene could be beyond the ability of most of the population. Studies in India have demonstrated that very few people brush twice and floss once daily [5].

Therefore many chemotherapeutic agents have been introduced such as essential oils, fluorides, bisbiguanides, sanguinarine, quaternary ammonium salts, and triclosan which help in prevention of periodontal diseases. Among them, chlorhexidine is regarded as gold standard in dentistry; however it has certain side effects such as brown discoloration of the teeth, oral mucosal erosion, and bitter taste [6]. Hence, there is a requirement of an alternative medicine.

Plant-based medicines emerged as new treatment modalities for periodontal diseases. This will help to overcome microbial drug resistance caused by misuse of chemotherapeutic agents.

Azadirachta indica (Neem) is the most useful traditional medicinal plant and considered as "Village dispensary" in India. Twigs of the neem (datoon) are used by a significant portion of the population to maintain oral hygiene [7].

Neem has been considered to have various activities such as antibacterial, astringent, antiseptic, insecticidal, anti-ulcer and for cleaning the teeth in pyorrhoea and other dental diseases [8].

Considering the above statements, this study was conducted using the purest and soluble form of neem to test its anti-plaque and anti-inflammatory properties in the form of a mouth gel.

\section{Materials and Methods}

The study was conducted in the Department of Periodontology, in collaboration with the Department of Oral and Maxillofacial Surgery, Faculty of Dental Sciences, King George's Medical University, Lucknow, India and National Botanical Research Institute, Lucknow. The study unit consisted of patients of chronic gingivitis. Anti-plaque and anti-gingivitis properties of Neem-based gel were compared with chlorhexidine (CHX) gel. Since chlorhexidine is considered to be gold standard among all available chemicals in prevention of gingivitis due to its antiplaque and anti-inflammatory properties, so we used to compare it with neem. 
A written consent was taken from all the participants. Before initiating the study each patient was informed about the purpose and design of the study.

\subsection{Sample Size}

Assuming $80 \%$ power, 5\% significance level (95\% confidence interval), the sample calculation.

Test revealed that $>11$ patients in each of the two groups. A total of 60 subjects (33 males and 27 females) from age group 19 - 35 years who met the following inclusion criteria were included:

Inclusion criteria: 1) subjects with mild to moderate gingivitis; 2) subjects having all the teeth erupted (third molars not included).

Exclusion criteria: 1) smokers; 2) subjects suffering from systemic diseases; 3) pregnant and lactating females; 4) subjects with oral habits such as bruxism, mouth breathing; 5) subjects wearing any appliances or prosthesis.

\subsection{Study Design}

Simple random sampling was followed and the participants were assigned to two groups.

Group A ( $\mathrm{n}=30)$ - participants were advised experimental (Neem) gel.

Group B $(n=30)$ - participants in this group were advised $0.2 \%$ chlorhexidine gel.

All the clinical parameters (the gingival index by Loe and Silness [1], Plaque index by Silness and Loe [2] and sulcus bleeding index by Muhlemann H. R. and Sen S. [3]) were recorded at baseline, on the $14^{\text {th }}$ day and $21^{\text {st }}$ day by the same clinician in both groups.

\subsection{Clinical Parameters}

Gingival index (Loe and Silness [1])—scoring criteria.

\begin{tabular}{cl}
\hline Score & Criteria \\
\hline 0 & Normal gingival. \\
1 & Mild inflammation: slight change in color and slight edema. No bleeding on probing. \\
2 & Moderate inflammation: redness, edema and Bleeding on probing. \\
3 & Severe inflammation: marked redness, edema and ulceration and spontaneous bleeding. \\
\hline
\end{tabular}

Plaque index (Silness and Loe [2]).

\begin{tabular}{cl}
\hline Score & Criteria \\
\hline 0 & $\begin{array}{l}\text { No plaque. } \\
1\end{array} \quad \begin{array}{l}\text { A film of plaque adhering to the free gingival margin and adjacent area of the tooth. The } \\
\text { plaque may be recognized by running a probe across the tooth surface. }\end{array}$ \\
2 & $\begin{array}{l}\text { Moderate accumulation of soft deposit within the gingival pocket and on the gingival } \\
\text { margin that can be seen by the naked eye. }\end{array}$ \\
3 & $\begin{array}{l}\text { Abundance of soft matter within the gingival pocket and or on the gingival margin and } \\
\text { adjacent tooth surface. }\end{array}$
\end{tabular}


Sulcus bleeding index (Muhlemann H. R. and Sen S. [3]).

\begin{tabular}{cl}
\hline Score & Criteria \\
\hline 0 & $\begin{array}{l}\text { Healthy gingival. } \\
\text { Apparently healthy papillary and margin gingiva showing no colors or contour change } \\
\text { and no swelling but bleeding on probing present. }\end{array}$ \\
2 & Bleeding on probing and color change caused by inflammation no swelling or edema. \\
3 & Bleeding on probing, change in color, slight edematous swelling. \\
4 & $\begin{array}{l}\text { Bleeding on probing, color change, obvious swelling. } \\
5\end{array}$ \\
& $\begin{array}{l}\text { Spontaneous bleeding on probing, color change, marked swelling with or without } \\
\text { ulceration. }\end{array}$ \\
\hline
\end{tabular}

\subsection{Preparation of Neem and Chlorhexidine Gel}

Preparation of gel: $12 \mathrm{gm}$ Xanthan gum was taken in a beaker and dispersed in $50 \mathrm{ml}$ of distilled water. Kept the beaker aside to swell the Xanthan gum for half an hour and then stirring should be done using stirrer at $1800 \mathrm{rpm}$ for $25 \mathrm{~min}$. Take $5 \mathrm{ml}$ of propylene glycol and required quantity of Extract. Take $5 \mathrm{ml}$ propylene glycol in another beaker and add weighed quantity of propyl paraben and methyl paraben to it and stirred properly. After all Xanthan gum dispersed, Extract (neem) and preservatives solutions were added with constant stirring, and to obtain the gel at required consistency.

Chlorhexidine gel (Elugel-0.2\%) was procured from Win-Medicare Pvt limited.

\subsection{Intervention}

Participants in both the groups received oral hygiene instruction along with fullmouth scaling and polishing immediately after the base line clinical assessment. Instructions for maintenance of oral hygiene were given. For a period of 21 days, the group A was advised to use neem gel and group B was advised to use chlorhexidine gel twice daily after brushing. The subjects were given demonstrations and trained regarding the application of the respective formulation to minimize the variation.

\subsection{Statistical Analysis}

The data were subjected to statistical analysis after tabulating the clinical data for the patients of both groups included in this study. Changes in clinical data are presented as mean \pm SD. Reduction in severity of gingivitis in the two groups was statistically tested for significance. Parametric tests (Student's t-test) were used for normally distributed data.

\subsection{Outcome Measures (Figure 1)}

\section{Plaque Index (PI)}

On intra group analysis (Table 1), the PI in Group A (Neem gel) decreases significantly after $2^{\text {nd }}$ and $3^{\text {rd }}$ week with mean $( \pm S D) 1.65 \pm 0.21$ and $2.01 \pm 0.16$, 


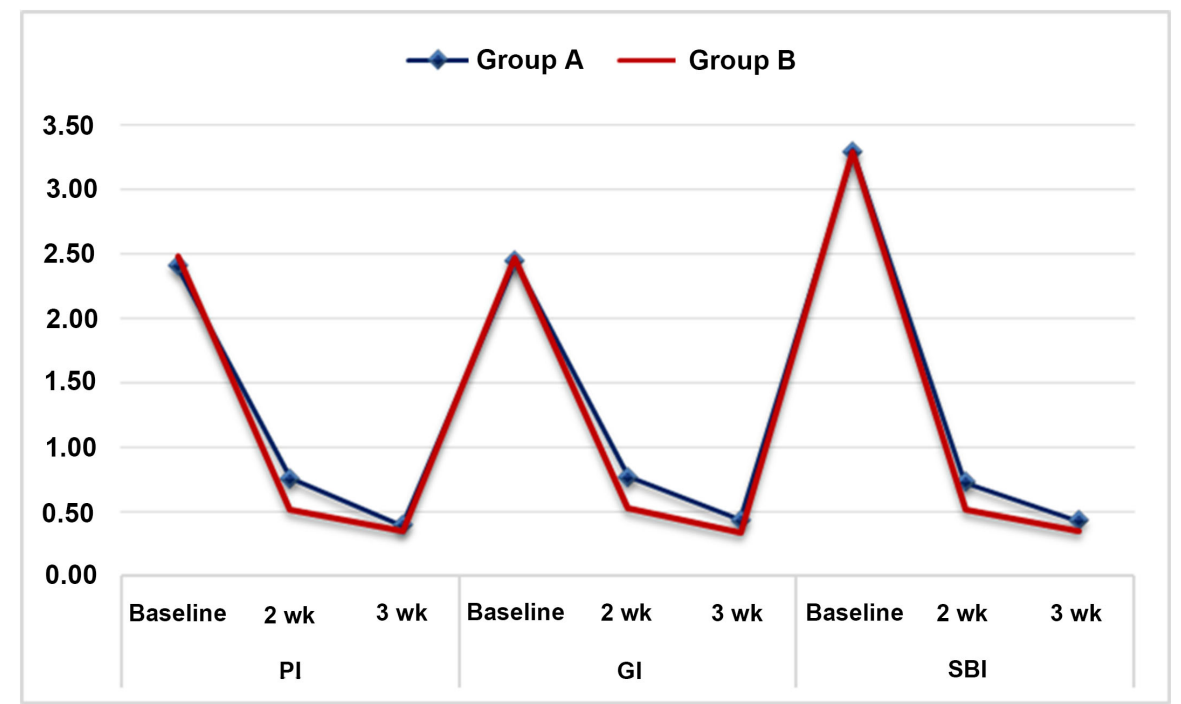

Figure 1. Comparison of periodontal parameters between group A (Neem) and group B (CHX).

Table 1. Intragroup analysis of Periodontal Parameters-PI, GI \& SBI in Group A.

\begin{tabular}{cccccc}
\hline \multirow{2}{*}{ Parameter } & Time & \multicolumn{4}{c}{ Group A (Neem) } \\
\cline { 3 - 6 } & & Mean Diff. & SD & t-value & $P$-value \\
\hline \multirow{2}{*}{ PI } & BL to 2 wk & 1.65 & 0.21 & 42.92 & $<0.001$ \\
& BL to 3 wk & 2.01 & 0.16 & 67.33 & $<0.001$ \\
& 2 wk to 3 wk & 0.36 & 0.22 & 9.14 & $<0.001$ \\
\hline \multirow{2}{*}{ GI } & BL to 2 wk & 1.67 & 0.16 & 58.97 & $<0.001$ \\
& BL to 3 wk & 2.00 & 0.12 & 91.99 & $<0.001$ \\
& 2 wk to 3 wk & 0.33 & 0.11 & 16.55 & $<0.001$ \\
\hline \multirow{2}{*}{ SBI } & BL to 2 wk & 2.56 & 0.24 & 57.44 & $<0.001$ \\
& BL to 3 wk & 2.86 & 0.20 & 78.16 & $<0.001$ \\
& 2 wk to 3 wk & 0.30 & 0.17 & 9.81 & $<0.001$ \\
\hline
\end{tabular}

respectively as compared to baseline. The mean PI significantly $(P<0.05)$ decreases by $0.36 \pm 0.22$ after 3 weeks as compared to 2 weeks. Similarly, in Group B (CHX gel), the PI decreases significantly after $2^{\text {nd }}$ and $3^{\text {rd }}$ week with mean $( \pm$ SD) $1.97 \pm 0.18$ and $2.13 \pm 0.17$, respectively as compared to baseline. The mean PI decrease significantly $(P<0.05)$ by $0.16 \pm 0.05$ after 3 weeks as compared to 2 weeks (Table 2).

Further, comparing the mean PI between the groups (Table 3), the PI did not differ $(P>0.05)$ between the two groups at baseline indicating that PI was comparable. After $2^{\text {nd }}$ week, the mean PI in Group B decrease more than the group A which was statistically significant $(P<0.001)$. However, after $3^{\text {rd }}$ week, the mean PI in Group B decrease more than the Group A which was statistically not significant $(P>0.05)$. 
Table 2. Intra group analysis of Periodontal Parameters-I, GI \& SBI in Group B.

\begin{tabular}{cccccc}
\hline \multirow{2}{*}{ Parameter } & Time & \multicolumn{4}{c}{ Group B (CHX) } \\
\cline { 3 - 6 } & & Mean Diff. & SD & t-value & $P$-value \\
\hline \multirow{2}{*}{ PI } & BL to 2 wk & 1.97 & 0.18 & 61.20 & $<0.001$ \\
& BL to 3 wk & 2.13 & 0.17 & 67.47 & $<0.001$ \\
& 2 wk to 3 wk & 0.16 & 0.05 & 18.68 & $<0.001$ \\
\hline \multirow{2}{*}{ GI } & BL to 2 wk & 1.95 & 0.13 & 83.04 & $<0.001$ \\
& BL to 3 wk & 2.14 & 0.12 & 96.51 & $<0.001$ \\
& 2 wk to 3 wk & 0.19 & 0.06 & 17.29 & $<0.001$ \\
\hline \multirow{2}{*}{ SBI } & BL to 2 wk & 2.78 & 0.18 & 85.06 & $<0.001$ \\
& BL to 3 wk & 2.94 & 0.16 & 102.13 & $<0.001$ \\
& 2 wk to 3 wk & 0.16 & 0.07 & 13.04 & $<0.001$ \\
\hline
\end{tabular}

Table 3. Intergroup comparison of periodontal parameters-PI, GI \& SBI between Group A and Group B.

\begin{tabular}{cccccccc}
\hline \multirow{2}{*}{ Parameter } & Time & \multicolumn{2}{c}{ Group A (Neem) } & \multicolumn{2}{c}{ Group B (CHX) } & \multirow{2}{*}{ t-value } & $P$-value \\
\cline { 3 - 6 } & & Mean & SD & Mean & SD & & \\
\hline \multirow{2}{*}{ PI } & Baseline & 2.41 & 0.12 & 2.48 & 0.17 & -2.01 & 0.049 \\
& $2 \mathrm{wk}$ & 0.76 & 0.15 & 0.51 & 0.04 & 8.61 & $<0.001$ \\
& $3 \mathrm{wk}$ & 0.40 & 0.11 & 0.35 & 0.05 & 1.95 & 0.056 \\
\hline \multirow{2}{*}{ GI } & Baseline & 2.44 & 0.12 & 2.47 & 0.13 & -0.88 & 0.384 \\
& $2 \mathrm{wk}$ & 0.77 & 0.10 & 0.52 & 0.02 & 13.79 & $<0.001$ \\
& $3 \mathrm{wk}$ & 0.44 & 0.07 & 0.33 & 0.06 & 6.19 & $<0.001$ \\
\hline \multirow{2}{*}{ SBI } & Baseline & 3.29 & 0.20 & 3.29 & 0.17 & 0.01 & 0.995 \\
& $2 \mathrm{wk}$ & 0.73 & 0.12 & 0.51 & 0.05 & 9.19 & $<0.001$ \\
& $3 \mathrm{wk}$ & 0.43 & 0.07 & 0.35 & 0.05 & 5.06 & $<0.001$ \\
\hline
\end{tabular}

\section{Gingival Index (GI)}

On intra group analysis (Table 1), the GI in Group A (neem gel) decreases significantly after $2^{\text {nd }}$ and $3^{\text {rd }}$ week with mean $( \pm S D) 1.67 \pm 0.16$ and $2.00 \pm 0.12$, respectively as compared to baseline. The mean GI significantly $(P<0.05)$ decreases by $0.33 \pm 0.11$ after 3 weeks as compared to 2 weeks. Similarly, in Group B (CHX gel), the GI decreases significantly after $2^{\text {nd }}$ and $3^{\text {rd }}$ week with mean $( \pm$ SD) $1.95 \pm 0.13$ and $2.14 \pm 0.12$, respectively as compared to baseline. The mean GI decrease significantly $(P<0.05)$ by $0.19 \pm 0.06$ after 3 weeks when compared to 2 weeks (Table 2).

Further, comparing the mean GI between the groups (Table 3), the GI did not differ $(P>0.05)$ between the two groups at baseline indicating that GI was comparable. However, after $2^{\text {nd }}$, the mean GI in CHX group $(0.52 \pm 0.02)$ decreases significantly $(P<0.001)$ more as compared to the neem gel group $(0.77 \pm 0.10)$. 
After $3^{\text {rd }}$ week, the mean GI in CHX group $(0.33 \pm 0.06)$ decreases significantly $(P<0.001)$ more as compared to the neem gel group $(0.44 \pm 0.07)$.

\section{Sulcular Bleeding Index (SBI)}

On intra group analysis (Table 1), the SBI in Group A (neem gel) decreases significantly after $2^{\text {nd }}$ and $3^{\text {rd }}$ week with mean $( \pm$ SD) $2.56 \pm 0.24$ and $2.86 \pm 0.20$, respectively as compared to baseline. The mean SBI significantly $(P<0.05)$ decreases by $0.30 \pm 0.17$ after 3 weeks as compared to 2 weeks.

Similarly, in Group B (CHX gel), the SBI decreases significantly after $2^{\text {nd }}$ and $3^{\text {rd }}$ week with mean $( \pm S D) 2.78 \pm 0.18$ and $2.94 \pm 0.16$, respectively, as compared to baseline. The mean SBI decreases significantly $(P<0.05)$ by $0.16 \pm 0.07$ after 3 weeks as compared to 2 weeks (Table 2).

Further, comparing the mean SBI between the groups (Table 3), the SBI did not differ $(P>0.05)$ between the two groups at baseline indicating that SBI was comparable. However, after $2^{\text {nd }}$ week, the mean SBI in CHX group $(0.51 \pm 0.25)$ decrease significantly $(P<0.001)$ more as compared to the neem gel group $(0.73$ $\pm 0.12)$. After 3 rd week, the mean GI in CHX group $(0.35 \pm 0.05)$ decreases significantly $(P<0.001)$ more as compared to the neem gel group $(0.43 \pm 0.07)$.

\section{Discussion}

The accumulation bacterial biofilm at the gingival margin is act as primary etiological factor in development of chronic gingivitis. Several chemical plaque control agents have been introduced to improve mechanical oral hygiene procedures. Chlorhexidine has been regarded as a "gold" standard in dentistry for the prevention of plaque and gingivitis. Chlorhexidine mouthwash though very effective also has certain side effects such as brown discoloration of the teeth and oral mucosal erosion [9].

Neem (Azadirachta indica), the versatile medicinal plant is the unique source of various types of compounds having diverse chemical structure. It has provided a new insight into the exploration and utilization of neem tree as a source for development of new therapeutic molecules.

Ethanolic leaf extract of neem shows significant antibacterial activity against selected acidogenic oral bacteria causing dental plaque in fixed orthodontic appliance patients [10].

This study was conducted to explore the clinical efficacy of neem gel in chronic gingivitis patients.

In our study, Group A (neem) and Group B (CHX) did not differ statistically in the demographic and periodontal conditions at baseline. No significant difference was observed in mean age between neem group and CHX group. The two groups were comparable and had not influenced the study outcome measures.

In contrast to our study, Balappanavar et al. (2013) [11] shown that on intra group analysis of neem group, decrease in PI at $3^{\text {rd }}$ week $(0.44 \pm 0.53)$ was nonsignificant when compared with baseline $(1.52 \pm 0.06)$. 
Chemical analyses of neem stick extract confirmed the presence of hydrolyzable tannins. The galloyl radical of the tannins was important for inhibition of glucan activity and anti-plaque activity of some tannins. Although mechanism of action of polyphenolic tannins as anti-plaque agent is not known clearly, it can be hypothesized that tannins effectively bind to surface associated bacterial proteins, which results in the formation of bacterial aggregates and loss of glucosyl transferase activity. Inhibition of glucosyl transferase activity could lead to decrease in plaque formation [12] [13].

Patel and Venkatakrishna (1988) [14] reported that Neem have better efficacy in reducing the human plaque cultures and gram-negative bacteria compared to the commercially available dentifrice. Chlorhexidine has been established as most effective antiplaque agent. It is broad spectrum antiseptic acting against gram + ve and gram - ve bacteria as well as fungi and viruses.

Comparing the mean PI between the groups, the PI did not differ $(P>0.05)$ between the two groups at baseline. However, after $2^{\text {nd }}$ week, the mean PI in CHX group decreases significantly $(P<0.001)$ more than neem group. After $3^{\text {rd }}$ week, the mean PI in CHX group decreases more than neem group which was non-significant $(P>0.05)$. This may be due to the property of substantivity of chlorhexidine and also the action of chlorhexidine at different levels of plaque formation.

In contrast to our study Balappanavar et al. (2013) [11] demonstrated that on intergroup comparison, decrease in mean PI significantly $(P<0.001)$ more in neem group than Chlorhexidine group at 2 weeks.

The use of gallotannin-enriched extract of neem results in aggregation of bacteria by inhibiting insoluble glucan synthesis. Neem gel act as anti-plaque agent by inhibiting the colonization of streptococci to the tooth surfaces and found to be beneficial in reducing the plaque index [15] [16] [17].

In our study, after intra group analysis of plaque index (PI), significant reduction was found in PI on reassessment (after $2^{\text {nd }}$ and $3^{\text {rd }}$ week) in neem group with mean $( \pm \mathrm{SD}) 1.65 \pm 0.21$ and $2.01 \pm 0.16$, respectively as compared to baseline. These results are consistent with the findings of other studies [18] [19] [20] [21], showing the anti-plaque effects of neem.

In our study, the anti-inflammatory action of neem was evaluated on clinical parameters using the Gingival Index (GI), which showed a significant reduction after $2^{\text {nd }}$ and $3^{\text {rd }}$ week with mean $( \pm S D) 1.67 \pm 0.16$ and $2.00 \pm 0.12$, respectively when compared with baseline. On intra group analysis, the SBI in Group A (neem gel) decreases significantly after $2^{\text {nd }}$ and $3^{\text {rd }}$ week with mean $( \pm S D) 2.56 \pm$ 0.24 and $2.86 \pm 0.20$, respectively as compared to baseline.

The study of Alam et al. (1999) [18] showed the anti-inflammatory activity of Neem against macrophase migration inhibitory factor and due to inhibition of the PMN oxidative burst [19].

Study conducted by Bhargava, K. P. et al. (1970) [20] demonstrated that neem significantly $(\mathrm{P}<0.001)$ reduce gingival inflammation after $3^{\text {rd }}$ week when compared with baseline similar to our study. In contrast to our study, Balappanavar 
(2013) [11] reported that neem decreases GI at 3rd week (1.0 \pm 0.5$)$ which was non-significant when compared with baseline (2.50 \pm 0.71$)$.

In our study the mean GI and SBI in both the groups decrease after the treatment, and the decrease was evident significantly $(P<0.001)$ higher in Group B (CHX) than Group A (neem). Antibacterial properties of neem help to remove many oral aerobic and anaerobic pathogens existing in the oral cavity.

In oppose to our results Chatterjee et al. (2011) [13] and Botelho et al. (2008) [12] shown that on comparison between neem group and CHX group, statistically no significant difference were observed in GI and SBI at 1 month after treatment. Similarly a systematic review also shows no significant statistical difference in PI and GI between neem and chlorhexidine after treatment. It may be due to quality of reporting of RCTs and quality of evidence for treatment outcomes were low raising concerns about study conductance and results [21].

Nimbidin, azadirachtin and nimbinin are active compounds present in Neem which are responsible for antibacterial activity. The chief active constituent of Neem is azadirachtin, which is an effective antimicrobial agent [22]. It is also effective against periodontal pathogens, and dental plaque. Also Botelho et al. [12] in their experiments and trials concluded that Azadirachta indica is highly efficacious in the treatment of periodontal disease and exhibiting its biocompatibility with human periodontal fibroblast [13].

Twigs of neem tree are used as chewing sticks by people all over India [23]. Neem bark and leaf extract is a remedy for tooth decay, oral infections, prevents bleeding and sore gums. Studies indicate that leaf extract of A. indica-based mouth rinse is highly efficacious and that it may be used as an alternative therapy in the treatment of periodontal disease [12].

\section{Conclusions}

Both the mouth gels (neem and chlorhexidine) used in our study were effective in the reduction of plaque and gingival inflammation in gingivitis patients. This study demonstrated the use of neem in treating the oral infections by inhibiting the plaque growth and anti-inflammatory activity. Thus, it can be used as an adjunct to mechanical therapy for treating plaque induced gingivitis. However, chlorhexidine gel showed better effectiveness in reducing plaque and gingivitis than neem gel due to its substantivity.

Further long-term studies on a large sample are required to evaluate the efficacy and substantivity of neem gel as anti-gingivitis agent.

\section{Acknowledgements}

The author extends the regards to Dr. Zeashan Zaidi (Assistant Professor, Era's Medical College, Lucknow, Uttar Pradesh, India) for the statistical analysis of data in this study.

\section{Conflicts of Interest}

The authors declare no conflicts of interest regarding the publication of this paper. 


\section{References}

[1] Loe, H. and Silness, J. (1963) Periodontal Disease in Pregnancy. I. Prevalence and Severity. Acta Odontologica Scandinavica, 21, 533-551. https://doi.org/10.3109/00016356309011240

[2] Macgregor, I.D. (1987) Comparison of the Silness-Loe (1964) Index with Gravimetric Measurement of Dental Plaque. Clinical Preventive Dentistry, 9, 9-12.

[3] Benamghar, L., Penaud, J., Kaminsky, P., Abt, F. and Martin, J. (1982) Comparison of Gingival Index and Sulcus Bleeding Index as Indicators of Periodontal Status. Bulletin of the World Health Organization, 60, 147-151.

[4] Albandar, J.M., Streckfus, C.F., Adesanya, M.R. and Winn, D.M. (2000) Cigar, Pipe, and Cigarette Smoking as Risk Factors for Periodontal Disease and Tooth Loss. Journal of Periodontology, 71, 1874-1881.

https://doi.org/10.1902/jop.2000.71.12.1874

[5] Oberoi, S.S., Mohanty, V., Mahajan, A., et al. (2014) Evaluating Awareness Regarding Oral Hygiene Practices and Exploring Gender Differences among Patients Attending for Oral Prophylaxis. Journal of Indian Society of Periodontology, 18, 369-374. https://doi.org/10.4103/0972-124X.134580

[6] Stoeken, J.E., Paraskevas, S. and van der Weijden, G.A. (2007) The Long-Term Effect of a Mouth Rinse Containing Essential Oils on Dental Plaque and Gingivitis: A Systematic Review. Journal of Periodontology, 78, 1218-1228.

https://doi.org/10.1902/jop.2007.060269

[7] Patel, S.M., Nagulapalli Venkata, K.C., Bhattacharyya, P., Sethi, G. and Bishayee, A. (2016) Potential of Neem (Azadirachta indica L.) for Prevention and Treatment of Oncologic Diseases. Seminars in Cancer Biology, 40-41, 100-115. https://doi.org/10.1016/j.semcancer.2016.03.002

[8] Subapriya, R. and Nagini, S. (2005) Medicinal Properties of Neem Leaves: A Review. Current Medicinal Chemistry-Anti-Cancer Agents, 5, 146-149. https://doi.org/10.2174/1568011053174828

[9] Francetti, L., del Fabbro, M., Testori, T. and Weinstein, R.L. (2000) Chlorhexidine Spray versus Chlorhexidine Mouthwash in the Control of Dental Plaque after Periodontal Surgery. Journal of Clinical Periodontology, 27, 425-430. https://doi.org/10.1034/j.1600-051x.2000.027006425.x

[10] Lakshmi, T., Krishnan, V., Rajendran, R. and Madhusudhanan, N. (2015) Azadirachta indica: A Herbal Panacea in Dentistry-An Update. Pharmacognosy Reviews, 9, 41-44. https://doi.org/10.4103/0973-7847.156337

[11] Balappanavar, A.Y., Sardana, V. and Singh, M. (2013) Comparison of the Effectiveness of $0.5 \%$ Tea, $2 \%$ Neem and $0.2 \%$ Chlorhexidine Mouthwashes on Oral Health: A Randomized Control Trial. Indian Journal of Dental Research, 24, 26-34. https://doi.org/10.4103/0970-9290.114933

[12] Botelho, M.A., dos Santos, R.A., Martins, J.G., et al. (2008) Efficacy of a Mouthrinse Based on Leaves of the Neem Tree (Azadirachta indica) in the Treatment of Patients with Chronic Gingivitis: A Double Blind, Randomized, Controlled Trial. Journal of Medicinal Plants Research, 2, 341-346.

[13] Chatterjee, A., Saluja, M., Singh, N. and Kandwal, A. (2011) To Evaluate the Antigingivitis and Antipalque Effect of an Azadirachta indica (Neem) Mouthrinse on Plaque Induced Gingivitis: A Double-Blind, Randomized, Controlled Trial. Journal of Indian Society of Periodontology, 15, 398-401.

https://doi.org/10.4103/0972-124X.92578 
[14] Patel, V.K. and Venkatakrishna-Bhatt, H. (1988) Folklore Therapeutic Indigenous Plants in Periodontal Disorders in India (Review, Experimental and Clinical Approach). International Journal of Clinical Pharmacology, Therapy, and Toxicology, 26, 176-184.

[15] Pai, M.R., Acharya, L.D. and Udupa, N. (2004) Evaluation of Antiplaque Activity of Azadirachta indica Leaf Extract Gel-A 6-Week Clinical Study. Journal of Ethnopharmacology, 90, 99-103. https://doi.org/10.1016/j.jep.2003.09.035

[16] Wolinsky Le Mania, S., Nachnani, S. and Ling, S. (1996) The Inhibiting Effect of Aqueous Azadirachta indica (Neem) Extract upon Bacterial Properties Influencing in Vitro Plaque Formation. Journal of Dental Research, 75, 816-822. https://doi.org/10.1177/00220345960750021301

[17] Elavarasu, S., Abinaya, P., Elanchezhiyan, S., Thangakumaran, Vennila, K. and Naziya, K.B. (2012) Evaluation of Anti-Plaque Microbial Activity of Azadirachta indica (Neem Oil) in Vitro: A Pilot Study. Journal of Pharmacy and Bioallied Sciences, 4, S394-S396. https://doi.org/10.4103/0975-7406.100299

[18] Almas, K. (1999) Antimicrobial Effects of Extracts of Azadirachta indica (Neem) and Salvadora persica (Arak) Chewing Sticks. Indian Journal of Dental Research, 10, 23-26.

[19] Kumar, V.S. and Navaratnam, V. (2013) Neem Azadirachta indica, Prehistory to Contemporary Medicinal Uses to Humankind. Asian Pacific Journal of Tropical Biomedicine, 3, 505-514. https://doi.org/10.1016/S2221-1691(13)60105-7

[20] Bhargava, K.P. et al. (1970) Anti-Inflammatory Activity of Saponins and Other Natural Products. The Indian Journal of Medical Research, 5S, 724-730.

[21] Dhingra, K. and Vandana, K.L. (2017) Effectiveness of Azadirachta indica (Neem) Mouthrinse in Plaque and Gingivitis Control: A Systematic Review. International Journal of Dental Hygiene, 15, 4-15. https://doi.org/10.1111/idh.12191

[22] Bhanwara, S., Singh, J. and Khosla, P. (2000) Antinociceptive Activity of Azadirachta indica (Neem) in Rats. Indian Journal of Physiology and Pharmacology, 18, 17-21.

[23] Sharma, P., Tomar, L., Bachwani, M. and Bansal, V. (2011) Review on Neem (Azadirechta indica, Thousand Problem One Solution. International Research Journal of Pharmacy, 2, 97-102. 